\title{
SÍMBOLO DA ÉTICA
}

\author{
Alcino Lázaro da Silva ${ }^{1}$
}

\begin{abstract}
"É isso que faz do estudante de medicina a figura mais desagradável da civilização moderna. Falta de respeito e de boas maneiras". *
\end{abstract}

George Bernard Shaw

Um bom médico se faz com berço saudável, formação ontoética e informação. O formado bem informado, mesmo sem um berço sustentável, também, se torna exemplar. A informação encontra-se na internet, revista ou em livros já estudados. Dispensa, pois, o professor tradicional. A formação, no entanto, necessita de uma referência, um orientador, um amadurecido para conduzir o jovem ao caminho da Ontoética - a ética do Ser! Deste parâmetro saem as bases e os princípios fundamentais da boa convivência, eficaz tolerância, equilíbrio psicossensitivo e atitude digna e humana ao se proceder o ato médico.

Os currículos no Brasil, até onde sei, preocupam-se com a informação, a informação especializada e a tecnologia. Formação humanística, produto do estudo e de leitura sobre as Humanidades em geral, não é considerada prioridade o que leva o aluno e o professor a não professarem ou a não vivê-la em plenitude.

Se não há estudo de Humanidades (por ex. Artes Cênicas, Artes Plásticas, Filosofia, Língua Portuguesa, Literatura, Música, Poesia, Política, Religiosidade...), não há convivência, tolerância e muito menos o azul, cor da paz, no trabalho e na relação médico-paciente.

Se nada disso se ensina, se aprende ou se exercita, o quotidiano fica sem a educação no trato pessoal, ou seja, sem a Etiqueta ou pequena ética.

Preocupados com isso, devemos nos lembrar de que o jovem precisa ser alertado, orientado e exemplificado nos princípios básicos da Etiqueta Médica. São toques de atitudes primárias mas que tornam a relação médico-paciente a muralha para sustentar o sucesso terapêutico e o respeito mútuo doentemédico. Como se comportar nos mais variados capítulos, v.g.: uso do avental, vestuário, cumprimentos, chamar pelo nome, cuidado com as mãos, uso da palavra, diálogo, não mascar, pontualidade, não assentar-se no leito, objetos sobre o leito, visita (e não corrida), encenação, sigilo, consentimento (consenso pleno), exames da mulher e do homem, intimidade, acompanhante, encaminhamento, opinião médica, equipe médica, telefone, família, esposo(a), secretária, enfermagem, paramédicos, funcionários, conversa de corredor, chefia e administração superiores, sociedades médicas, convênios, SUS, representante de laboratório, conflito de interesse, convidado, relacionamento com aluno, professor e doente, sala de aula, na rua, no lazer, política, filantropia, funeral, internet, correio médico, tolerância, agradecimento, honorário, cultura geral...
O exercício médico, calcado em atitudes sadias e estas em princípios fundamentais, torna-se eficaz, humano e respeitado. A conseqüência é o retorno maior que o médico pode almejar, ou seja, ser considerado e reconhecido pelo seu paciente e familiares.

A Ética existe desde que o homem olhou nos olhos do outro (alteridade). Ela, ao que eu saiba, além da filosofia dos grandes pensadores, possui todos os princípios lembrados acima, mas não tem o seu Símbolo, ainda definido. Estamos propondo, então, discutirmos esse assunto com base na exposição que se segue.

Desde os Pré-Socráticos fala-se, preocupa-se, pregase e estuda-se Ética. O mundo inteiro fala em Ética. Esta possui desdobramentos, dentro da Filosofia, que se sucedem, se interrelacionam ou se completam: Valor, Moral, Ética, Deontologia, Diceologia, Ética na Pesquisa, Bioética, Ontoetica, Comunidade Azul. Toda essa seqüência retrata uma insatisfação, um vazio espiritual e uma incompletude menteespírito.

A civilização contemporânea, no afogadilho para a solução de problemas, na complexidade do dia-a-dia, na angustia de realizações imediatas, na falta de introspecção ou reflexão, clama por Ética. Ética é a palavra em todos os setores e em todas as profissões. O lugar-comum retrata, pois , uma identidade de anseios.

Refletindo sobre o tema ocorreu-nos uma curiosidade. A pergunta é se existe um símbolo para a Ética, desde que é requisitada por todos? Não encontramos, ou não temos conhecimento, ainda. Admitindo-se a hipótese de não haver nenhuma proposta, nada custa pensar sobre o assunto e propor algo para discussão.

$\mathrm{O}$ que seria mais adequado e coerente com o objetivo da Ética? Teria de ser um representativo com equanimidade ("Aequaenimitas"), biológica, mental, espiritual e transcendental ou preternatural. Qual o elemento da natureza, com essas características, em que a homeóstase se observa, tanto interna como externamente e na sua interelação com o ecossistema? Uma semente? Uma flor? Um fruto? Uma árvore? Uma pedra? Um animal? O ar? O fogo ? A água? A terra?... Cada um por si sem influências maléficas do entorno, poderia simbolizar a Ética, pois são equilibrados na sua biologia e na sua ecointegração. Alguns deles, facilmente, conseguimos materializar no esquema ou no desenho. Para outros é 
impossível.

Preocupado com o desafio, lembrei-me da pessoa mais eticamente bem formada que a humanidade teve conhecimento. Nasceu eticamente; cresceu eticamente; viveu eticamente; procedeu eticamente; exemplificou-se eticamente; pregou ética; resguardou os valores éticos e morreu eticamente. Ele foi a própria, pura e completa Ética. Jesus Cristo! A imagem divina no homem: "prudentia, justitia, moderatio, virtus, sapientia, disciplina”. (Carl Gustav Jung)

Usar a sua imagem para misturar-se com os nossos valores incipientes não seria respeitoso. Lembramo-nos, então, de uma figura tranqüila, fluente, convivente, discreta, societária, respeitosa aos valores da comunidade, prolífica e compartilhante: o peixe. O simbolismo bíblico da água reforça essa idéia:

"A terra estava sem forma e vazia; as trevas cobriam o abismo e um vento impetuoso soprava sobre as águas". (Gn $1 ; 2)$.

"Os filhos de Israel entravam pelo mar a pé enxuto, e as águas formavam duas muralhas, à direita e à esquerda". (Ex $14,22)$

"Pois o meu povo praticou dois crimes: abandonaram a mim, fonte de água viva, e cavaram para si poços, poços rachados que não seguram a água". (Jr 2,13)

Além disso o próprio nome - PEIXE - pode representar Jesus Cristo.

XPTO, era na Idade Média a redução do nome de Cristo e usado como símbolo do Cristianismo, confundindo-se o "qui" (X) com o "xis" (X) e o "ro" (P) com o "P" latino.

Desde os tempos em que os cristãos se refugiavam nas catacumbas, perdura o monograma ICHTHYS - que significa peixe e era usado como senha.

Desdobrado lê-se: "Iesoûs Christós Theou Yiós Sotér", ou seja, Jesus Cristo Filho de Deus Salvador, cujas primeiras letras são as gregas: iota, qui, teta, ípsilon e sigma (J. A. Vasconcelos)

Se Aquele personagem que mudou a humanidade, com a sua Ética absoluta, perene, eterna e imutável, tem o nome vinculado a ICHTHYS, peixe, nada mais adequado do que considerarmos este animal como símbolo desta mesma ética. E que ela possa nortear o caminhar dos povos rumo à sua plena realização e integração.

Julgamos poder sugerir que o peixe deveria ser o Símbolo da Ética pela sua identificação com a Ética de Cristo e porque o seu nome pode representar Jesus Cristo.

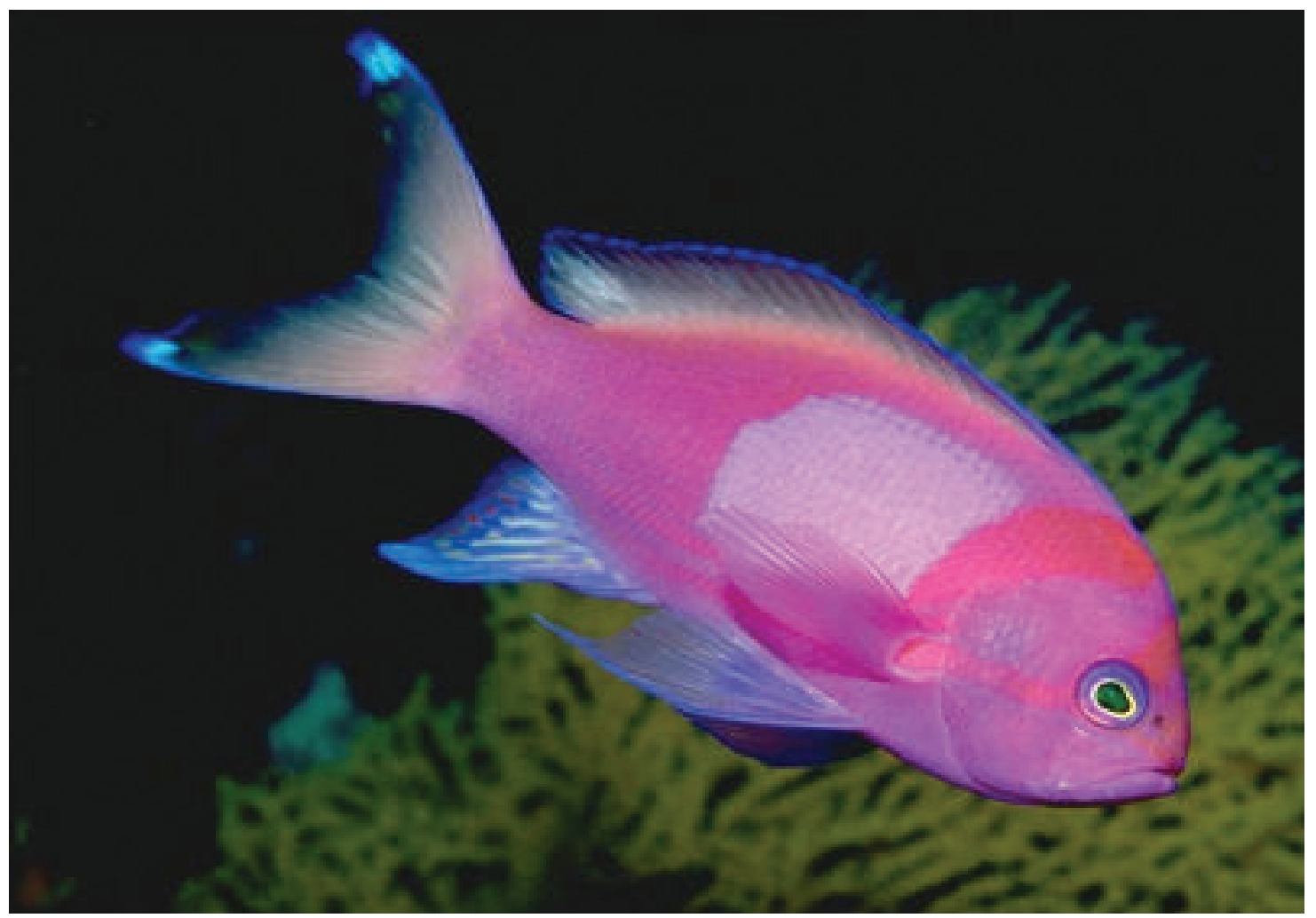

${ }^{1}$ Professor Titular de Cirurgia do Aparelho Digestivo - Universidade Federal de Minas Gerais [UFMG].

Presidente da Diretoria Central da Sobradpec.

*Lázaro da Silva A. Etiqueta médica. Belo Horizonte: Fundação Unimed; 2004. 